\title{
Probabilistic Assessment of Lightning Related Risk of Transmission Lines Based on Frequency Dependent Modeling of Tower-Footing Grounding System
}

\author{
Javad Gholinezhad $^{1}$, Reza Shariatinasab ${ }^{2, *}$, Keyhan Sheshyekani $^{3}$ \\ ${ }^{1,2}$ Department of Electrical and Computer Engineering, University of Birjand, Birjand, Iran \\ ${ }^{3}$ Department of Electrical Engineering, Polytechnique Montréal University, Montreal, Canada \\ *corresponding author, E-mail: Shariatinasab@birjand.ac.ir
}

\begin{abstract}
This paper presents a probabilistic evaluation, based on Monte-Carlo method, for the estimation of insulation risk of failure of overhead transmission lines $(T L S)$. The proposed method takes into account the wide-band model of towerfooting grounding system. The wide-band model of grounding system in frequency domain is obtained by the method of moment solution to the governing electrical field integral equations. The electrical parameters of soil are considered to be either constant or frequency dependent. The time-domain representation of the grounding system is inferred through pole-zero characterization of its associated frequency response. The case of a typical $400-\mathrm{kV}$ transmission line is modelled in EMTP_RV with the towerfooting grounding system integrated with the transmission line $(T L)$ system. The results of the paper show that the failure risk of transmission lines is affected by the grounding system model. This effect is more pronounced when the soil electrical parameters are assumed to be frequency dependent.
\end{abstract}

\section{Introduction}

Lightning overvoltages are the leading cause of insulation failure in transmission lines (TLs). Therefore, lightning protection systems of TLs should be properly designed to reduce the maintenance services and the need to replacement of damaged equipment [1]. Lightning failures can be caused by strokes to shield wire, tower body or phase conductors. The lightning phenomenon is characterized by its stochastic nature mainly in terms of the parameters of its return stroke current and the stroke location. Hence, a probabilistic approach is usually adopted to evaluate the lightning performance of TLs.

So far, extensive studies have been carried out on the risk assessment and lightning performance of TLs in order to design the proper lightning protection system [2-7]. In the previous works the grounding system has been modeled with a linear or nonlinear resistor [2-5]. However, a method has also been presented in [8-10] for wide band modelling of grounding systems in the EMTP-like tools. This helps with the accurate calculation of lightning overvoltages.

In this paper, the statistical parameters of lightning are taken into account and insulation failure risk is estimated by a link connected between MATLAB environment and EMTP RV program. In order to go through this, the grounding system of tower of transmission line is modeled in static-model (ST model), wide-band model assuming constant electrical parameters for the soil (CP model), and wide-band model assuming frequency-dependent electrical parameters for the soil (FD model). However, the calculation of the lightning related failure risk is carried out based on the Monte-Carlo method.

\section{Lightning Related Studies}

\subsection{Lightning Parameters}

The peak value $\left(I_{P}\right)$, rise time $\left(t_{f}\right)$ and time to half value $\left(t_{h}\right)$ are the main parameters of the lightning waveforms, in which the statistical variation of each of the above parameters is approximated by a log-normal distribution [11]:

$$
p(x)=\frac{1}{\sigma_{\ln x} \sqrt{2 \pi} x} \exp \left\{-\frac{1}{2}\left(\frac{\ln x-\ln \bar{x}}{\sigma_{\ln x}}\right)^{2}\right\},
$$

Where $\sigma_{\operatorname{lnx}}$ and $\bar{x}$ are the standard deviation and median value of each lightning parameter $x$, respectively.

The statistical data of lightning parameters can be adopted from Table 1. The statistical distribution of subsequent strokes in a flash can be selected based on the distribution given in [11].

Table 1: Statistical parameters of Multi-stroke Negative Lightning Flashes [11].

\begin{tabular}{ccc|cc}
\hline \multirow{2}{*}{ Parameters } & \multicolumn{2}{c}{ First stroke } & \multicolumn{2}{c}{$\begin{array}{c}\text { Subsequent } \\
\text { stroke }\end{array}$} \\
\cline { 2 - 5 } & Median & $\sigma_{\operatorname{lnx}}$ & Median & $\sigma_{\operatorname{lnx}}$ \\
$I_{p}(k A)$ & 31.1 & 0.48 & 13 & 0.6447 \\
$t_{f}(\mu s)$ & 3.83 & 0.55 & 0.32 & 0.6677 \\
$t_{h}(\mu s)$ & 75 & 0.58 & 20 & 0.69 \\
\cline { 2 - 5 }$\rho_{c^{*}}\left(I_{p}, t_{f}\right)$ & \multicolumn{2}{c}{0.47} & \multicolumn{3}{c}{0} \\
\hline
\end{tabular}

\subsection{Termination Point of Impacts}

It is assumed that lightning strokes are uniformly distributed on an impact area, Fig. 1, where its width $Y_{\max }$ is limited by 
a distance that corresponds to the maximum peak current magnitude and derived from the electro-geometric model (EGM) of transmission line [4,5]. The length of the impact area is the line span. Having the point of lightning occurrence on the ground, termination point of impact (stroke to ground, shield or phase conductor) can be determined. In Fig. $1, R_{g}$ and $R_{c}$ are striking distances to the conductors and ground, respectively [12].

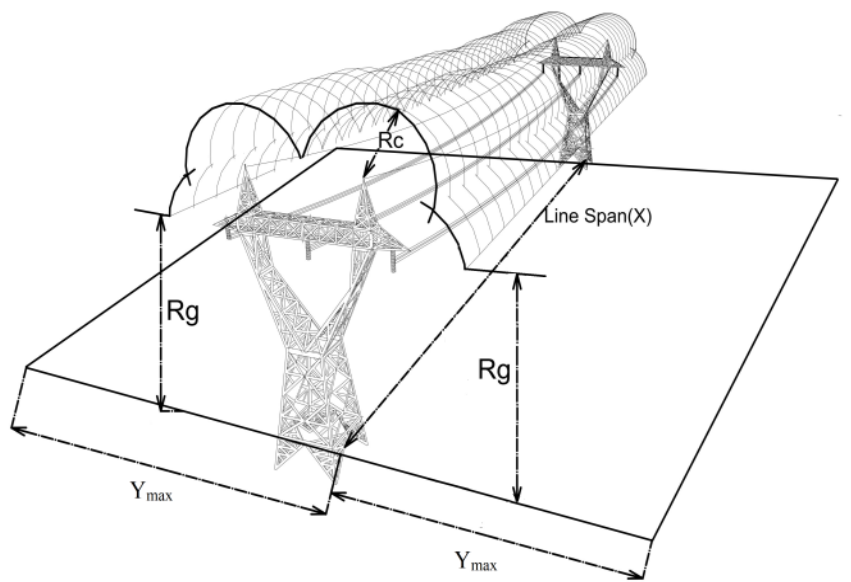

Figure 1: Impact area of lightning strokes on the ground.

\section{Transmission Line Components Modeling}

\subsection{Transmission Tower}

The schematic diagram of a typical tower of the $400 \mathrm{kV}$ test line and its resultant multistory model is shown in Fig. 2. In the multistory model, $Z_{t 1}(=200 \Omega)$ is the surge impedance between the tower top to the phase and $Z_{t 2}(=150 \Omega)$ is the surge impedance between phase arm to the tower bottom. Further details regarding for the values of $R$ and $L$ can be found in [13].

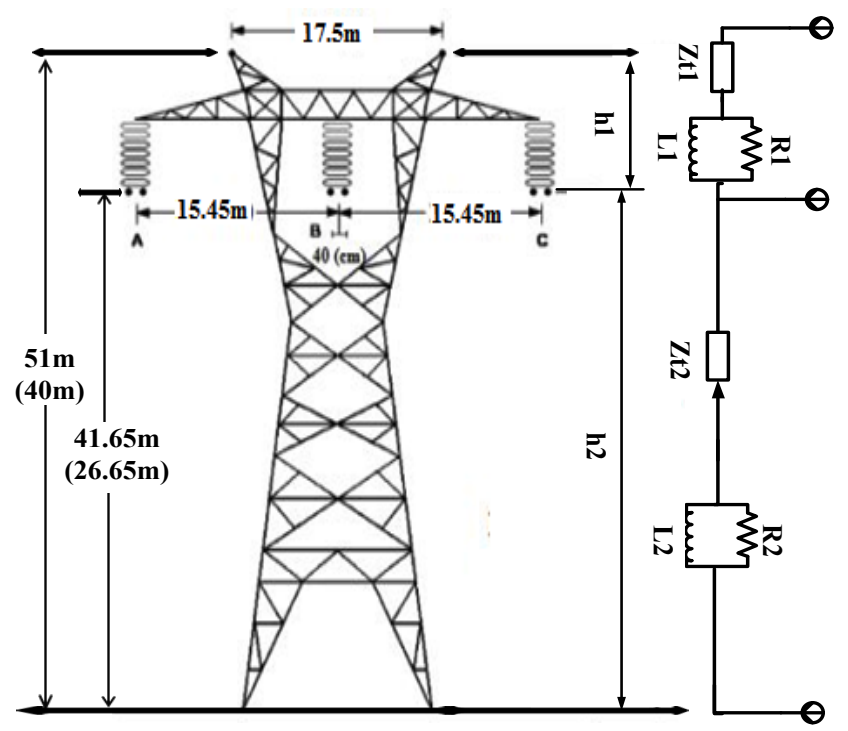

(a)

(b)

Figure 2: (a) Tower configuration (values in brackets are midspan heights), (b) multistory model of transmission tower.

\subsection{Insulator String Flashover Characteristic}

The insulator string modeling of transmission line affects the calculation of the failure risk caused by lightning surges. The insulator string can be modeled as a voltage controlled switch connected to a parallel capacitor, as shown in Fig. 3 [14]. If the peak value of the lightning current exceeds a socalled critical current, the insulator experiences the flashover that closes the switch in parallel with the capacitor.

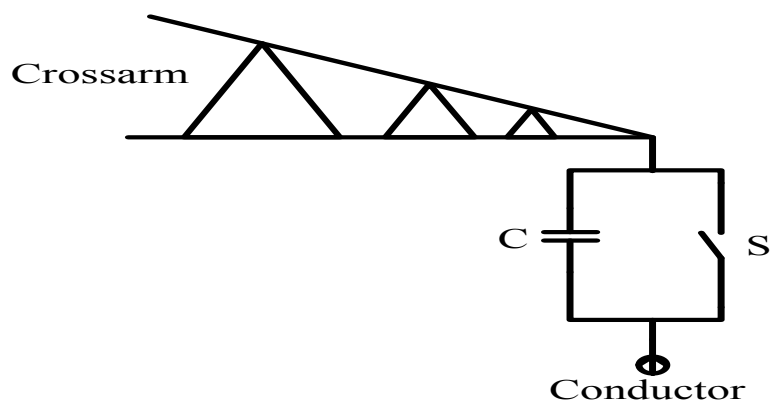

Figure 3: Insulator string model of $T L$.

In this paper, the integration method is used for evaluation the effect of non-standard lightning overvoltages. The integration method is expressed as follows [14]:

$$
D E=\int_{t_{0}}^{t}\left(V(t)-V_{0}\right)^{k} d t,
$$

Where $D E\left(k v^{k} \cdot \mu s\right)$ is the disruptive effect of the applied impulse voltage, $t_{0}(\mu \mathrm{s})$ is the instant that the instantaneous voltage $V(t)$ exceeds the minimum voltage $V_{0}$ beyond which the breakdown process starts; and $k$ is a factor accounting for the effects of the applied voltage amplitude and time on $D E$.

In the integration method, breakdown occurs when the integral $(D E)$ becomes equal to or higher than the critical disruptive effect $D E^{*}$. Table 2 presents the adopted values of constant parameters of the integration method, from which $\mathrm{K}=1.36$ is adopted in this paper.

Table 2: The value of Parameters of Integration method

\begin{tabular}{cccc}
\multicolumn{3}{c}{ in $400-\mathrm{kV}[14]}$. \\
\hline \multicolumn{3}{c}{$\mathrm{K}=1.36$} & $\mathrm{~K}=2.5$ \\
\hline$V_{0}(k V)$ & $D E^{*}\left(* 10^{3} . k V^{1.36}\right.$ & $V_{0}(k V)$ & $D E^{*}\left(* 10^{6} . k V^{2.5}\right.$. \\
& $. \mu s)$ & & $\mu s)$ \\
1363 & 30.061 & 849.7 & 213.579 \\
\hline
\end{tabular}

\subsection{Tower Footing Impedance}

For the lightning related studies, the tower footing impedance conventionally is modelled by a simple nonlinear resistance in which the soil ionization is a function of the instantaneous current flows through the tower footing [4,5,15-17]. In this modeling, the frequency dependence behavior of the soil electrical parameters is ignored [18][20]. Concerning the frequency dependence of soil 
electrical parameters, the model proposed by Longmire and Smith is used [21]. It is supposed that in the adopted model the working frequency interval changes over DC to $2 \mathrm{MHz}$. The grounding system is modeled either by its static model (ST) or its wide-band model. In the case of static modeling, the grounding system is modeled by resistance equal to the low frequency value of the impedance magnitude of the tower footing grounding system. The wide-band modeling refers to $C P$-wide-band ( $C P$ model) where the soil electrical parameters are assumed to be constant or FD-wide-band ( $F D$ model) where the soil electrical parameters are assumed to be frequency dependent as suggested by Longmire model. Further detail on wide-band modeling of tower footing grounding system can be found in [9]. It must be mentioned that in the current work the soil ionization is disregarded.

\section{Modelling of Grounding System}

To calculate the admittance matrix of grounding system over the desired frequency interval, the Method of Moments (MoM) can be used to solve the Electric Field Integral Equation (EFIE). The same procedure of [9] is used to determine the admittance matrix of the grounding system as

$$
Y(s)=Z^{-1}(s)=\left(\begin{array}{ccc}
a_{11}(s) & \ldots & a_{1 n}(s) \\
\mathrm{M} & 0 & \mathrm{M} \\
a_{n 1}(s) & \mathrm{L} & a_{n n}(s)
\end{array}\right)
$$

where $n$ is the number of ports of the grounding system while aij(s) $(i=j)$ and $\operatorname{aij}(s)(i \neq j)$ respectively denote the self and mutual admittances for and between ports $i$ and $j$. The reader is referred to [9] for further details. Following the procedure of [9], the state space model of the grounding system admittance matrix is developed for the time domain simulation in EMTP.RV. The overall procedure involves rational fitting of the admittance matrix and then constitution of the state-space model in the form of

$$
\begin{aligned}
& \mathbf{R}(t)=\mathbf{A} \cdot \mathbf{x}(t)+\mathbf{B} \cdot \mathbf{v}(t) \\
& \mathbf{i}(t)=\mathbf{C} \cdot \mathbf{x}(t)+\mathbf{D} \cdot \mathbf{v}(t)+\mathbf{E} \cdot \mathbf{t}(t)
\end{aligned}
$$

where $x(t)$ is the state vector while $v(t)$ and $i(t)$ hold the voltage and current vectors of each port of the grounding system (see [22] for further details).

It must be mentioned that the state-space equations can be implemented in EMTP_RV, directly [9].

\section{Failure Risk Analysis}

Due to random nature of lightning parameters, Monte Carlo simulation is an appropriate tool for the lightning-related studies. Assuming the impact area of Fig. 1, Monte Carlo simulation can be summarized as: 1) generating random values of lightning flash parameters and coordination of the first stroke lightning stepped leader (x, y) on the impact area; 2) application of an Electro-geometric model (EGM) to determine termination point of impact of each lightning stroke; assuming that the subsequent strokes follow the same path of the first stroke [23]; 3) estimating the overvoltages generated by the lightning strokes, depending on the termination point of impact; 4) calculating the insulation failure risk.

The overall process of the proposed method is presented in Fig. 4.

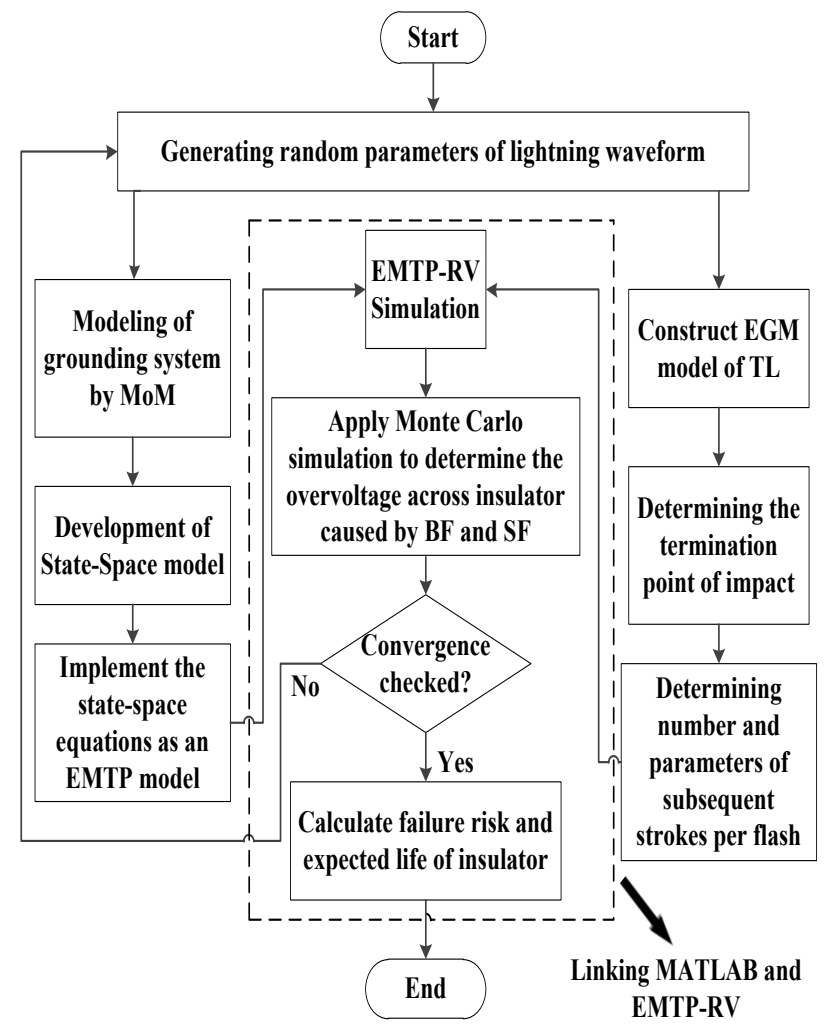

Figure 4: Flowchart of the proposed method.

The insulation failure risk (F.R.) that is the sum of the failure risks caused by back-flashover (BF) and shielding failure (SF) can be calculated by [4]:

$$
F . R .=\int_{V_{\min }}^{V_{\max }} f(V) P(V) d V,
$$

where $P(V)$ is the disruptive discharge probability of insulator string; $f(V)$ is the probability density functions of all overvoltages caused by either $S F$ or $B F ; V_{M i n}$ and $V_{M a x}$ are the minimum and maximum overvoltages produced across the insulator string.

\section{Numerical Results}

\subsection{Frequency domain simulation}

Fig. 5 presents the variation of grounding impedance for a vertical copper rod with $7 \mathrm{~mm}$ radius, as a function of the frequency.

It can be seen that the grounding impedance is almost constant up to $100 \mathrm{kHz}$ and increases for the greater frequencies. Also, the variation of grounding impedance proportional to the frequency is more intense for longer electrodes. 


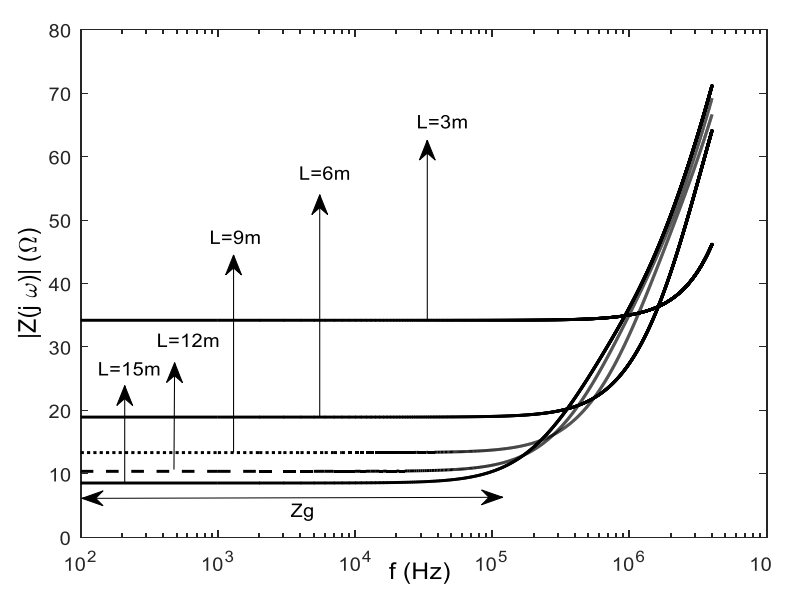

(a) Grounding impedance magnitude

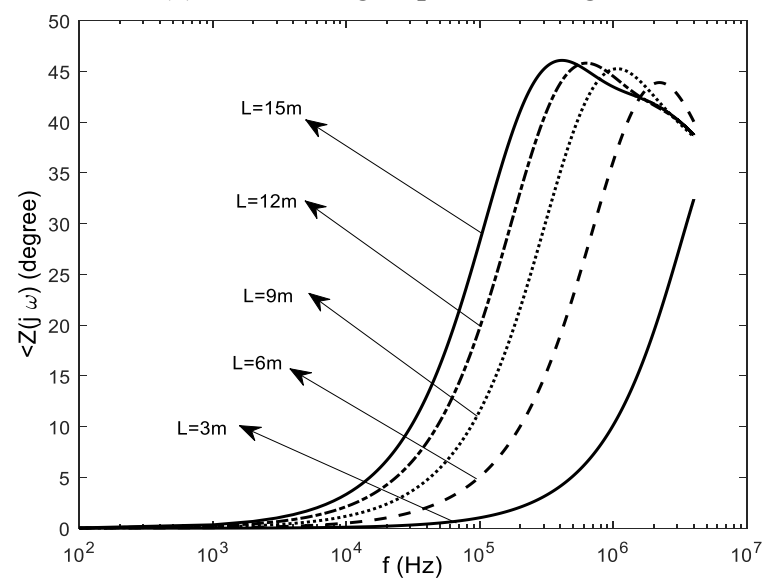

(b) Grounding impedance phase

Figure 5: Variation of grounding impedance for different vertical electrode lengths (soil resistivity $\rho=100$ $\Omega . \mathrm{m}$ and relative permittivity $\varepsilon_{r}=10$ ).

In Fig. 6, the variation of grounding impedance for a vertical rod electrode with $7 \mathrm{~mm}$ radius is shown for the soil with different resistivity.

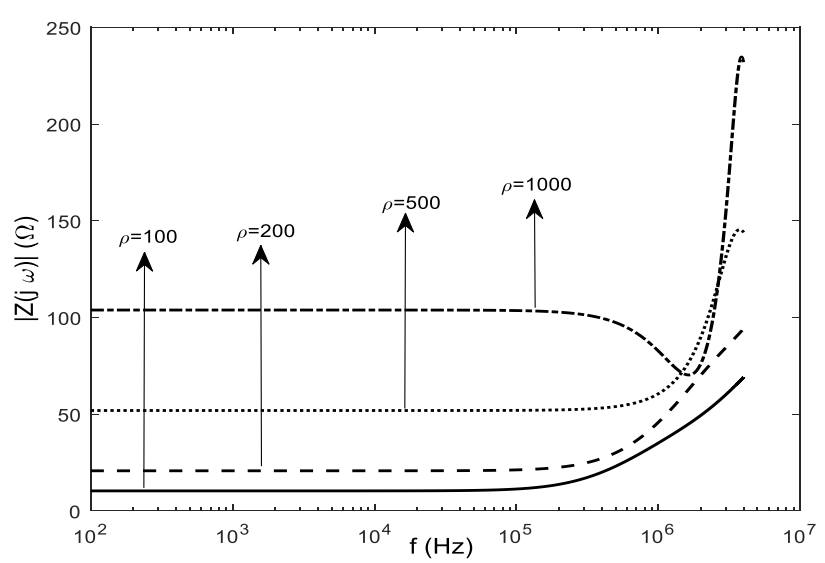

(a) Grounding impedance magnitude

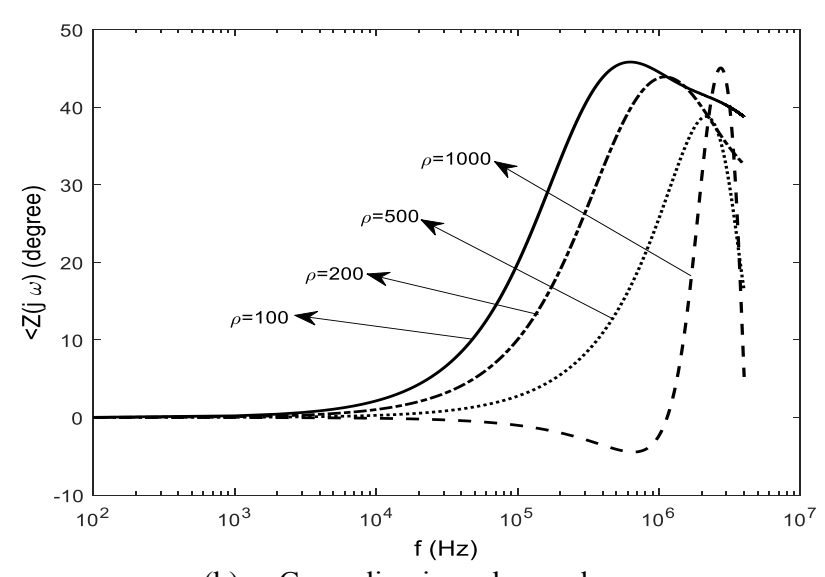

(b) Grounding impedance phase

Figure 6: Variation of grounding impedance for different soil resistivity (rod length $=12 \mathrm{~m}$ and relative permittivity $\varepsilon_{r}$ $=10$ ).

The same as the obtained results of Fig. 5, one can see that the grounding impedance remains constant up to $100 \mathrm{kHz}$ frequency while increases for the greater frequencies. Also, it can be seen that for the frequencies greater than $100 \mathrm{kHz}$, the behavior of rod electrode buried in the soil with high resistivity $(\rho=1000 \Omega . m)$ is firstly capacitive and then is inductive.

\subsection{Time domain simulation}

The presented method in this paper is performed for risk analysis of a typical $400 \mathrm{kV}$ transmission line, Fig. 2, with the basic lightning impulse insulation level (BIL) of 1450 $\mathrm{kV}$. The line specifications are also shown in Table 3.

Table 3: Line conductor characteristic.

\begin{tabular}{cccc}
\hline & Type & $\begin{array}{c}\text { Diameter } \\
(\mathrm{cm})\end{array}$ & $\begin{array}{c}\text { Resistance } \\
\Omega / \mathrm{km}\end{array}$ \\
\hline $\begin{array}{c}\text { Phase } \\
\text { conductors }\end{array}$ & CURLEW & 3.163 & 0.05501 \\
Shield wire & $94 \mathrm{~S}$ & 1.26 & 0.642 \\
\hline
\end{tabular}

The towers are represented by multi-story model and the transmission line is modeled by J. Marti's model [24]. The Heidler function [25] is also used to represent the lightning current waveform. At first, the procedure involves the estimation of the admittance matrix of grounding system and the representation of its state-space model to be incorporated in the EMTP_RV software.

In order to perform the Monte Carlo simulation, different parameters of each lightning stroke and location of lightning occurrence on the impact area, Fig. 1, is obtained. Thereafter, the EGM model of $T L$ is constructed for each of the lightning stokes separately and termination point of impact of each lightning stroke (ground, phase conductor and tower) is determined. The aforementioned steps are performed in MATLAB environment. Once the termination point of impact of each stroke has been determined, the EMTP simulation is performed to estimate the overvoltages. It must be noted that the subsequent strokes are simulated 
only for the flashes where the first stroke did not cause flashover.

To obtain the lightning parameters statistically, values of each parameter is produced randomly according to its theoretical distribution presented in Table 1. The convergence of the Monte Carlo simulation is checked by comparing the probability density function of random variables to their theoretical functions. In this paper, a $\% 5$ of error is set to stop the procedure. For example, Fig. 7 presents the distribution of random values of peak current magnitude and rise time with their associated correlation, for the first lightning stroke.

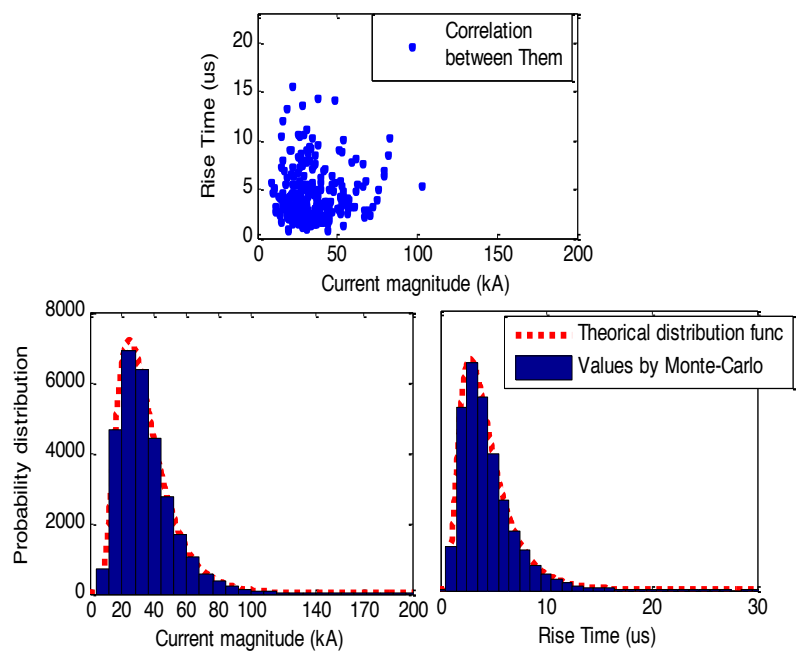

Figure 7: Distribution of generated random values of the first lightning stroke.

The grounding system of each tower is modeled in the EMTP_RV using the procedure described in the preceding sections. The analyses are done for a one-port vertical rod and a four-port simple square grid grounding systems, as shown in Fig. 8 [26].
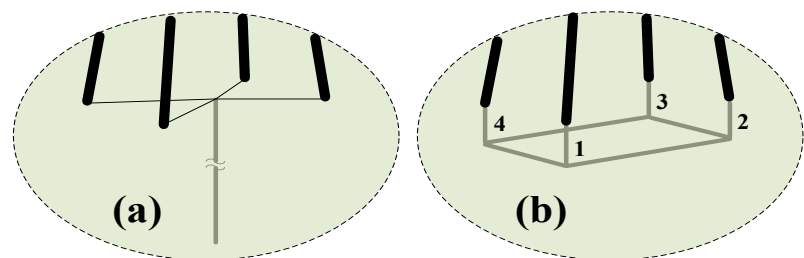

Figure 8: a) one-port $15 \mathrm{~m}$ (and $3 \mathrm{~m}$ ) vertical rod, b) fourport $6 \mathrm{mx} 6 \mathrm{~m}$ square grid, used for tower-footing grounding systems of all towers.

A sensitivity analysis on the behaviour of the vertical grounding rod with $12.5 \mathrm{~mm}$ radius and relative permittivity $\varepsilon r=10$, has been carried out, in which the result is shown in Fig. 9. Owing the results, it is clear that for decreasing the inductive behaviour of grounding system, shorter electrode must be used; and for the electrodes with length of equal or shorter than $3 \mathrm{~m}$, the grounding system is capacitive. However, this is not useful practically; as to achieve the low tower footing resistance in power frequency, longer electrodes must be used.

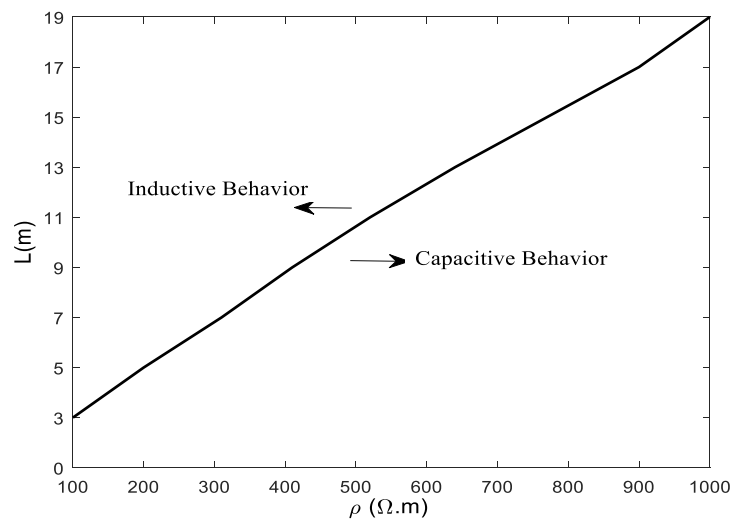

Figure 9: Inductive and capacitive behavior of vertical grounding rod as a function of the length and soil resistivity.

The transmission line tower is first assumed to have a rodshaped footing grounding system. The length of the grounding rod is $15 \mathrm{~m}$ with a circular cross section radius of $12.5 \mathrm{~mm}$. Three different soil resistivities; $\rho=100 \Omega \mathrm{m}, \rho$ $=500 \Omega \mathrm{m}$ and $\rho=1000 \Omega \mathrm{m}$ are used for simulation, all having the same relative permittivity of $\varepsilon r=20$.

The Matrix Pencil Method (MPM) [27] is used for the polezero identification of the calculated admittances based upon which the state-space block of the grounding system which is constructed for the EMTP_RV.

A sensitivity analysis, Tables 4-6, was performed to study the influence of lightning parameters and different modelling of grounding system on the maximum voltage produced across the insulator string, while the lightning surge hits to shield wires. To investigate both of the inductive and capacitive behaviors of the grounding system, the analysis was performed for rod length of $15 \mathrm{~m}$ and $3 \mathrm{~m}$.

Following conclusions can be made from the above results:

- It is clear that the wide band modeling of grounding system significantly affects on the lightning overvoltages produced across the insulator string. It can be seen that the difference between the results than to static model is more pronounced especially in the case of frequency dependent modeling of the soil electrical parameters, i.e. FD model.

- The effect of wide-band modeling on produced overvoltages depends on the capacitive or inductive behavior of the grounding systems which, in turn, is a function of the ground electrode length and soil resistivity.

- However, the wide band modeling is most effective on grounding system with capacitive behavior, especially for soil with high resistivity.

Fig. 10 presents the maximum voltages produced across the insulator string caused by the lightning first stroke, for different types of grounding system model. It is noted that, due to the tower configuration, the critical current is $60 \mathrm{kA}$. Then, lightning currents hitting to the phase conductor did not exceed $60 \mathrm{kA}$. 

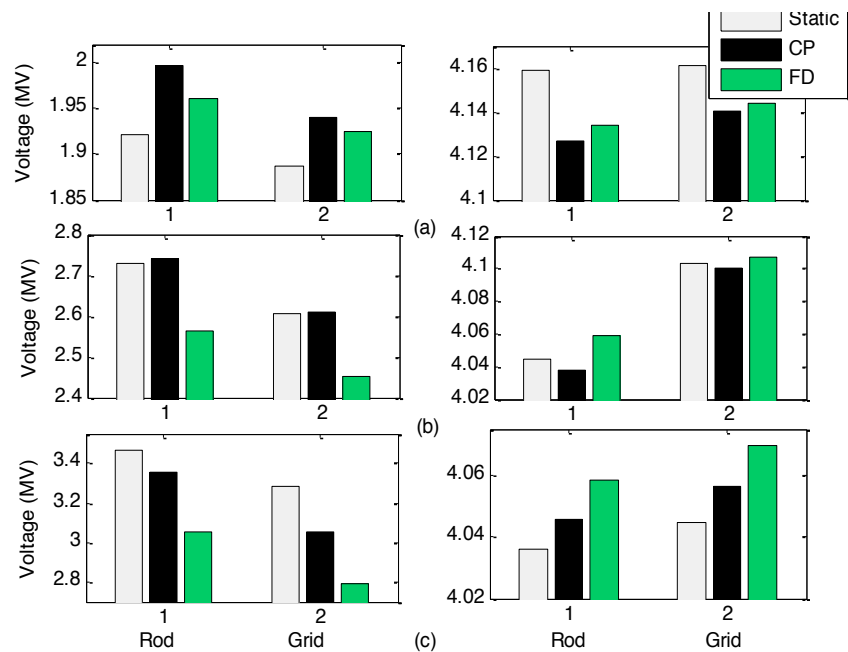

Figure 10: Maximum overvoltage across the insulator string, Left column: Stroke to shield wire: First stroke (100 $\mathrm{kA} \backslash 3.83 \mu \mathrm{s} \backslash 75 \mu \mathrm{s})$, Right column: Stroke to phase conductor:
First stroke (60 kA $\backslash 3.83 \mu \mathrm{s} \backslash 75 \mu \mathrm{s})$. case 1 for Rod-shape (15m) and case 2 for Grid shape grounding system. (a) $\rho=100 \Omega . m$, (b) $\rho=500 \Omega . m$, (c) $\rho=1000 \Omega . m$.

It can be seen that the effect of wide band modeling of grounding system is more pronounced when the soil electrical parameters are considered to be frequency dependent for the soils with high resistivity and especially for the grid shape grounding system.

From the results of Fig. 10, it is clear that for the lightning strokes to the shield wires, the generated overvoltages across the insulator string increase as the soil resistivity increases; also the obtained overvoltages for the grid-shaped grounding system are generally lower than the rod-shaped grounding system. However, for the strokes to phase conductors the resultant overvoltages are reduced with increasing the soil resistivity and the maximum overvoltages for the grid-shaped grounding system are higher than those of the rod-shaped grounding system.

Table 4: Maximum voltage across the insulator string $(\mathrm{kV})$ for Rod-shape grounding system.

\begin{tabular}{|c|c|c|c|c|c|c|c|c|c|}
\hline \multirow{4}{*}{$\begin{array}{c}\text { Soil } \\
\text { resistivity } \\
(\Omega \mathrm{m})\end{array}$} & \multirow{4}{*}{$\begin{array}{l}\text { Grounding } \\
\text { system } \\
\text { modeling }\end{array}$} & \multicolumn{7}{|c|}{ lightning surge parameter } & \\
\hline & & \multicolumn{2}{|c|}{$\begin{array}{c}I p=40 \mathrm{kA}, t_{f}=3.83 \mu \mathrm{s}, \\
t_{h}=75 \mu \mathrm{s}\end{array}$} & \multicolumn{2}{|c|}{$\begin{array}{c}\text { Variation of } \\
\text { overvoltages (\%) }\end{array}$} & \multicolumn{2}{|c|}{$\begin{array}{c}I p=100 \mathrm{kA}, \\
t_{f}=3.83 \mu \mathrm{s}, t_{h}=75 \mu \mathrm{s}\end{array}$} & & \\
\hline & & \multicolumn{3}{|c|}{ Rod length } & \multirow[b]{2}{*}{$15 \mathrm{~m}$} & \multicolumn{4}{|c|}{ Rod length } \\
\hline & & $3 \mathrm{~m}$ & $15 \mathrm{~m}$ & $3 \mathrm{~m}$ & & $3 \mathrm{~m}$ & $15 \mathrm{~m}$ & $3 \mathrm{~m}$ & $15 \mathrm{~m}$ \\
\hline \multirow{3}{*}{$\rho=100$} & ST & 1395 & 1205 & \multicolumn{2}{|c|}{ Base Case } & 2464 & 1868 & \multicolumn{2}{|c|}{ Base Case } \\
\hline & $\mathrm{CP}$ & 1390 & 1229 & -0.35 & 1.95 & 2445 & 1936 & -0.77 & 3.51 \\
\hline & FD & 1372 & 1218 & -1.67 & 1.06 & 2384 & 1904 & -3.35 & 1.89 \\
\hline \multirow{3}{*}{$\rho=1000$} & ST & 2472 & 1659 & \multicolumn{2}{|c|}{ Base Case } & 5860 & 3434 & \multicolumn{2}{|c|}{ Base Case } \\
\hline & $\mathrm{CP}$ & 2504 & 1633 & 1.27 & -1.59 & 5880 & 3314 & 0.34 & -3.62 \\
\hline & FD & 2153 & 1556 & 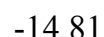 & -6.61 & 5112 & 2990 & -1463 & -14.84 \\
\hline
\end{tabular}

Table 5: Maximum voltage across the insulator string $(\mathrm{kV})$ for Rod-shape grounding system.

\begin{tabular}{|c|c|c|c|c|c|c|c|c|c|}
\hline \multirow{4}{*}{$\begin{array}{c}\text { Soil } \\
\text { resistivity } \\
(\Omega \mathrm{m})\end{array}$} & \multirow{4}{*}{$\begin{array}{l}\text { Grounding } \\
\text { system } \\
\text { modeling }\end{array}$} & \multicolumn{7}{|c|}{ lightning surge parameter } & \\
\hline & & \multicolumn{2}{|c|}{$\begin{array}{c}I p=40 \mathrm{kA}, t_{f}=1.8 \mu \mathrm{s}, \\
t_{h}=75 \mu \mathrm{s}\end{array}$} & \multicolumn{2}{|c|}{$\begin{array}{c}\text { Variation of } \\
\text { overvoltages (\%) }\end{array}$} & \multicolumn{2}{|c|}{$\begin{array}{c}I p=40 \mathrm{kA}, t_{f}=6 \mu \mathrm{s}, \\
t_{h}=75 \mu \mathrm{s}\end{array}$} & & \\
\hline & & \multicolumn{4}{|c|}{ Rod length } & \multicolumn{4}{|c|}{ Rod length } \\
\hline & & $3 \mathrm{~m}$ & $15 \mathrm{~m}$ & $3 \mathrm{~m}$ & $15 \mathrm{~m}$ & $3 \mathrm{~m}$ & $15 \mathrm{~m}$ & $3 \mathrm{~m}$ & $15 \mathrm{~m}$ \\
\hline \multirow{3}{*}{$\rho=100$} & ST & 1446 & 1209 & \multicolumn{2}{|c|}{ Base Case } & 1332 & 1140 & \multicolumn{2}{|c|}{ Base Case } \\
\hline & $\mathrm{CP}$ & 1436 & 1252 & -0.69 & 3.43 & 1327 & 1170 & 1436 & 1252 \\
\hline & FD & 1408 & 1237 & -2.69 & 2.26 & 1310 & 1158 & 1408 & 1237 \\
\hline \multirow{3}{*}{$\rho=1000$} & ST & 2677 & 1793 & \multicolumn{2}{|c|}{ Base Case } & 2346 & 1588 & \multicolumn{2}{|c|}{ Base Case } \\
\hline & $\mathrm{CP}$ & 2686 & 1741 & 0.33 & -2.98 & 2355 & 1554 & 2686 & 1741 \\
\hline & FD & 2312 & 1620 & -15.78 & -10.67 & 2060 & 1488 & 2312 & 1620 \\
\hline
\end{tabular}

Table 6: Maximum voltage across the insulator string $(\mathrm{kV})$ for Rod-shape grounding system.

\begin{tabular}{|c|c|c|c|c|c|c|c|c|c|}
\hline \multirow{4}{*}{$\begin{array}{c}\text { Soil } \\
\text { resistivity } \\
(\Omega \mathrm{m})\end{array}$} & \multirow{4}{*}{$\begin{array}{l}\text { Grounding } \\
\text { system } \\
\text { modeling }\end{array}$} & \multicolumn{7}{|c|}{ lightning surge parameter } & \multirow[b]{2}{*}{$\begin{array}{c}\text { Variation of } \\
\text { overvoltages (\%) }\end{array}$} \\
\hline & & \multicolumn{2}{|c|}{$\begin{array}{c}I p=40 \mathrm{kA}, t_{f}=3.83 \mu \mathrm{s}, \\
t_{h}=30 \mu \mathrm{s}\end{array}$} & \multicolumn{2}{|c|}{$\begin{array}{c}\text { Variation of } \\
\text { overvoltages (\%) }\end{array}$} & \multicolumn{3}{|c|}{$\begin{array}{c}I p=40 \mathrm{kA}, \\
t_{f}=3.83 \mu \mathrm{s}, t_{h}=150 \mu \mathrm{s}\end{array}$} & \\
\hline & & \multicolumn{3}{|c|}{ Rod length } & \multirow[b]{2}{*}{$15 \mathrm{~m}$} & \multicolumn{4}{|c|}{ Rod length } \\
\hline & & $3 \mathrm{~m}$ & $15 \mathrm{~m}$ & $3 \mathrm{~m}$ & & $3 \mathrm{~m}$ & $15 \mathrm{~m}$ & $3 \mathrm{~m}$ & $15 \mathrm{~m}$ \\
\hline \multirow{3}{*}{$\rho=100$} & ST & 1396 & 1206 & \multicolumn{2}{|c|}{ Base Case } & 1395 & 1205 & \multicolumn{2}{|r|}{ Base Case } \\
\hline & $\mathrm{CP}$ & 1390 & 1230 & -0.43 & 1.95 & 1390 & 1229 & 13 & $0 \quad 1230$ \\
\hline & FD & 1373 & 1219 & -1.67 & 1.06 & 1372 & 1218 & 13 & 1219 \\
\hline \multirow{3}{*}{$\rho=1000$} & ST & 2459 & 1659 & \multicolumn{2}{|c|}{ Base Case } & 2476 & 1659 & \multicolumn{2}{|r|}{ Base Case } \\
\hline & $\mathrm{CP}$ & 2478 & 1633 & 0.76 & -1.59 & 2511 & 1633 & 247 & 1633 \\
\hline & FD & 2104 & 1556 & -16.87 & -6.61 & 2166 & 1556 & 210 & 1556 \\
\hline
\end{tabular}


The distribution of lightning overvoltages caused by shielding failure and back-flashover for different grounding systems are obtained by Monte Carlo simulation (Tables 7 and 8). For every simulation, depending on the termination point of impact, the maximum value of voltage is stored and, finally, from each maximum voltage set obtained for all simulations, the distribution of the overvoltages is found. All results are obtained after 30000 runs. It is assumed that the density function of the overvoltages has a normal distribution [6]:

$$
f(V)=\frac{1}{\sigma \sqrt{2 \pi}} \exp \left[-\frac{\left(V-V_{50 \%}\right)^{2}}{2 \sigma^{2}}\right],
$$

Having known the voltage distribution, the failure risk of insulation can be calculated by (8). It is noted that once the probability of failure has been determined, the expected life (E.L.) can be calculated by:

$$
E . L .=N_{g} \frac{1}{F . R .},
$$

where $N_{g}$ is the number of flashes $/ 100 \mathrm{~km} /$ year.

Table 7: Lightning overvoltage distribution $(\mathrm{kV})$ for Different Modelling of Rod-shape $(15 \mathrm{~m})$ Grounding

\begin{tabular}{|c|c|c|c|c|c|c|}
\hline \multirow{2}{*}{$\begin{array}{c}\text { Soil } \\
\text { resistivity }(\Omega \mathrm{m})\end{array}$} & \multirow{2}{*}{$\begin{array}{l}\text { Grounding } \\
\text { system } \\
\text { modeling }\end{array}$} & & \multicolumn{2}{|c|}{ First Stroke } & \multicolumn{2}{|c|}{ Subsequent Stroke } \\
\hline & & & $\begin{array}{l}\text { Mean } \\
\text { value }\end{array}$ & $\begin{array}{l}\text { Standard } \\
\text { deviation }\end{array}$ & $\begin{array}{l}\text { Mean } \\
\text { value }\end{array}$ & $\begin{array}{l}\text { Standard } \\
\text { deviation }\end{array}$ \\
\hline \multirow{6}{*}{$\rho=100$} & \multirow{2}{*}{$\mathrm{ST}$} & $\mathrm{BF}$ & 1121.5 & 304.7 & 786.8 & 330 \\
\hline & & $\mathrm{SF}$ & 1456.6 & 165 & 1300 & 521.6 \\
\hline & \multirow{2}{*}{$\mathrm{CP}$} & $\mathrm{BF}$ & 1136.5 & 306.8 & 816.6 & 329 \\
\hline & & $\mathrm{SF}$ & 1455.9 & 165 & 1297.5 & 520.2 \\
\hline & \multirow{2}{*}{ FD } & $\mathrm{BF}$ & 1130.2 & 308.7 & 802.3 & 337 \\
\hline & & SF & 1456.2 & 165 & 1298.4 & 521 \\
\hline \multirow{6}{*}{$\rho=500$} & \multirow{2}{*}{ ST } & $\mathrm{BF}$ & 1250.1 & 304.7 & 889.1 & 377 \\
\hline & & SF & 1455 & 166.6 & 1295 & 532.5 \\
\hline & \multirow{2}{*}{$\mathrm{CP}$} & $\mathrm{BF}$ & 1254.4 & 306.8 & 890 & 378 \\
\hline & & SF & 1454.8 & 167.5 & 1295 & 529 \\
\hline & \multirow{2}{*}{ FD } & $\mathrm{BF}$ & 1233.5 & 306 & 877 & 377 \\
\hline & & SF & 1455.9 & 166.5 & 1297.8 & 534 \\
\hline \multirow{6}{*}{$\rho=1000$} & \multirow{2}{*}{$\mathrm{ST}$} & $\mathrm{BF}$ & 1321 & 283.6 & 972.2 & 412.1 \\
\hline & & $\mathrm{SF}$ & 1458.8 & 169.7 & 1287.3 & 532 \\
\hline & \multirow{2}{*}{$\mathrm{CP}$} & $\mathrm{BF}$ & 1311.7 & 287.1 & 954.6 & 400.4 \\
\hline & & SF & 1459.3 & 169.9 & 1287.9 & 531.5 \\
\hline & \multirow{2}{*}{ FD } & $\mathrm{BF}$ & 1289.6 & 249.9 & 917.2 & 405.2 \\
\hline & & SF & 1460.2 & 168.9 & 1289.9 & 532 \\
\hline
\end{tabular}
system.

\begin{tabular}{|c|c|c|c|c|c|c|}
\hline \multirow{2}{*}{$\begin{array}{c}\text { Soil } \\
\text { resistivity }(\Omega \mathrm{m})\end{array}$} & \multirow{2}{*}{$\begin{array}{l}\text { Grounding } \\
\text { system } \\
\text { modeling }\end{array}$} & & \multicolumn{2}{|c|}{ First Stroke } & \multicolumn{2}{|c|}{ Subsequent Stroke } \\
\hline & & & $\begin{array}{l}\text { Mean } \\
\text { value }\end{array}$ & Standard deviation & $\begin{array}{l}\text { Mean } \\
\text { value }\end{array}$ & Standard deviation \\
\hline \multirow{4}{*}{$\rho=100$} & ST & SF & 1459.1 & 151 & 1301 & 533 \\
\hline & \multirow{2}{*}{$\mathrm{CP}$} & $\mathrm{BF}$ & 1126.4 & 305 & 814.5 & 331.1 \\
\hline & & SF & 1444.6 & 142.6 & 1299.2 & 527.9 \\
\hline & FD & $\mathrm{SF}$ & 1456.4 & 164.8 & 1299.7 & 526.2 \\
\hline \multirow{4}{*}{$\rho=500$} & \multirow{2}{*}{ ST } & $\mathrm{BF}$ & 1236 & 308.3 & 876.7 & 352.2 \\
\hline & & SF & 1456 & 167 & 1297.7 & 526.7 \\
\hline & \multirow{2}{*}{$\mathrm{CP}$} & $\mathrm{BF}$ & 1239.3 & 307.8 & 878.5 & 353.3 \\
\hline & & $\mathrm{SF}$ & 1455.9 & 167 & 1296.6 & 561.8 \\
\hline \multirow{5}{*}{$\rho=1000$} & ST & SF & 1457.7 & 169.2 & 1294.1 & 534 \\
\hline & \multirow{2}{*}{$\mathrm{CP}$} & $\mathrm{BF}$ & 1290.1 & 292 & 924.9 & 398.2 \\
\hline & & $\mathrm{SF}$ & 1457.8 & 168.6 & 1295.2 & 532.4 \\
\hline & \multirow{2}{*}{ FD } & $\mathrm{BF}$ & 1256.3 & 301.7 & 888.5 & 399 \\
\hline & & SF & 1458 & 168.6 & 1296.2 & 533 \\
\hline
\end{tabular}

Table 8: Lightning overvoltage distribution (kV) for Different Modelling of Grid-shape Grounding System. 
Table 9: Insulation Failure Risk (F.R.) for Different Modelling of Rod-shape (15m)

\begin{tabular}{|c|c|c|c|c|c|}
\hline \multirow{2}{*}{$\begin{array}{c}\text { Soil } \\
\text { resistivity }(\Omega \mathrm{m})\end{array}$} & \multirow{2}{*}{$\begin{array}{c}\text { Grounding } \\
\text { system } \\
\text { model }\end{array}$} & \multicolumn{2}{|c|}{$\begin{array}{l}\text { Only First } \\
\text { Stroke }\end{array}$} & \multicolumn{2}{|c|}{$\begin{array}{l}\text { First and Subsequent } \\
\text { Strokes }\end{array}$} \\
\hline & & $\begin{array}{l}\text { F.R } \\
(\%)\end{array}$ & $\begin{array}{c}\text { Variation } \\
\text { of E.L. } \\
\text { (years) }\end{array}$ & $\begin{array}{l}\text { F.R } \\
(\%)\end{array}$ & $\begin{array}{l}\text { Variation } \\
\text { of E.L. } \\
\text { (years) }\end{array}$ \\
\hline \multirow{3}{*}{$\rho=100$} & ST & 9.340 & Base Case & 11.99 & Base Case \\
\hline & $\mathrm{CP}$ & 10.36 & $\approx-5$ & 13.31 & $\approx-4$ \\
\hline & FD & 10.00 & $\approx-3.5$ & 12.82 & $\approx-3$ \\
\hline \multirow{3}{*}{$\rho=500$} & ST & 17.99 & Base Case & 23.02 & Base Case \\
\hline & $\mathrm{CP}$ & 18.93 & $\approx-1.5$ & 24.04 & $\approx-1$ \\
\hline & FD & 16.26 & $\approx+3$ & 21.12 & $\approx+2$ \\
\hline \multirow{3}{*}{$\rho=1000$} & ST & 22.56 & Base Case & 31.17 & Base Case \\
\hline & $\mathrm{CP}$ & 21.73 & $\approx+1$ & 29.35 & $\approx+1$ \\
\hline & FD & 18.29 & $\approx+5$ & 24.97 & $\approx+4$ \\
\hline
\end{tabular}

Table 10: Insulation Failure Risk (F.R.) for Different Modelling of Grid-shape Grounding System, $\left(\mathrm{N}_{\mathrm{g}}=5\right)$.

\begin{tabular}{|c|c|c|c|c|c|}
\hline \multirow{2}{*}{$\begin{array}{c}\text { Soil } \\
\text { resistivity }(\Omega \mathrm{m})\end{array}$} & \multirow{2}{*}{$\begin{array}{l}\text { Grounding } \\
\text { system } \\
\text { model }\end{array}$} & \multicolumn{2}{|c|}{$\begin{array}{l}\text { Only First } \\
\text { Stroke }\end{array}$} & \multicolumn{2}{|c|}{$\begin{array}{c}\text { First and Subsequent } \\
\text { Strokes }\end{array}$} \\
\hline & & $\begin{array}{l}\text { F.R } \\
(\%)\end{array}$ & $\begin{array}{l}\text { Variation } \\
\text { of E.L. } \\
\text { (years) }\end{array}$ & $\begin{array}{l}\text { F.R } \\
(\%)\end{array}$ & $\begin{array}{c}\text { Variation } \\
\text { of E.L. } \\
\text { (years) }\end{array}$ \\
\hline \multirow{3}{*}{$\rho=100$} & $\mathrm{ST}$ & 8.87 & Base Case & 11.53 & Base Case \\
\hline & $\mathrm{CP}$ & 9.81 & $\approx-5$ & 12.66 & $\approx-4$ \\
\hline & FD & 9.58 & $\approx-4$ & 12.33 & $\approx-3$ \\
\hline \multirow{3}{*}{$\rho=500$} & ST & 16.41 & Base Case & 20.61 & Base Case \\
\hline & $\mathrm{CP}$ & 16.60 & $\approx 0$ & 20.86 & $\approx-0.5$ \\
\hline & FD & 15.29 & $\approx+2$ & 19.23 & $\approx+2$ \\
\hline \multirow{3}{*}{$\rho=1000$} & ST & 21.43 & Base Case & 28.55 & Base Case \\
\hline & $\mathrm{CP}$ & 20.13 & $\approx+1.5$ & 26.24 & $\approx+1.5$ \\
\hline & FD & 17.66 & $\approx+5$ & 22.89 & $\approx+4.5$ \\
\hline
\end{tabular}

The failure risk (F.R.) and the expected lifetime (E.L.) of the test line are calculated and shown in Tables 9 and 10 for rod-shape and grid-shape grounding system, respectively. Owing to the obtained results, the wide-band modeling of grounding system could change the failure risk of insulators compared to the case of static modeling. It should be pointed out that for the soils with low resistivity $(\rho=100 \Omega . m)$ the considered grounding systems reveal an inductive behavior, i.e., taking higher values at high frequencies. Hence, the failure risk for the case of wide-band model is expected to be higher than that of the static model. In other words, the expected lifetime obtained for the case of wide-band decreases. The decrement of the expected lifetime depends on the ground flash density. In general, the higher the ground flash density, the less the lifetime is expected. Similarly, and referring to the same interpretation, when the capacitive behavior of the grounding system is more dominant (the case of soil with $\rho=1000 \Omega . \mathrm{m}$ ), we expect lower risk values for the case of wide-band model ground as compared with the case of static model (see Tables 9 and 10). The results presented for the first and subsequent strokes show the same behavior in terms of the risk values and expected lifetime.

\section{Conclusion}

A probabilistic procedure has been performed in this paper for the lightning related failure risk calculation of TLs insulators, considering the wide band model for two types of tower footing grounding systems namely a vertical grounding rod and a simple square grid were studied.

To this aim, first the frequency dependence admittance matrix of grounding system was calculated by the method of Moments solutions to governing electric field integral equation. Then, the pole-residue identification of the admittance matrix of the tower footing grounding system was obtained and its associated state-space equations were incorporated into the EMTP_RV software.

The proposed probabilistic approach was established based on the Monte Carlo simulation, in which at first, random values of lightning parameters were generated and termination point of impact of each lightning stroke (phase conductors, shield wires, or ground) were determined by mean of EGM model of transmission lines. Thereafter, the produced overvoltage for each stroke was calculated by EMTP_RV. In this study, the subsequent strokes were only 
considered for the lightning flashes where the first stroke did not cause flashover. Finally, the failure risk of insulation was calculated. The model of Longmire and Smith was adopted for the frequency-dependent soil parameters.

From the results, it was found that the wide-band model of the tower-footing grounding system can affect (either decrease or increase) the insulation risk and the expected lifetime of insulation of TLs. This effect is mainly determined by the grounding system structure, ground flash density and the soil electrical parameters. However, the wide band modeling is most effective on grounding system with capacitive behavior consisting of short electrodes, especially for soil with high resistivity.

\section{References}

[1] A.R. Hileman, Insulation coordination for power systems, Marcel Dekker, New York, USA, 1999.

[2] A.O. Fernandez, S.B. Bogarra, M.A. GrauGotes, Optimization of surge arrester's location, IEEE Trans. Power Deliv. 19(1): 145-150, 2004.

[3] E. Perez, A. Delgadillo, D. Urrutia, A. Torres, Optimizing the surge arresters location for improving lightning induced voltage performance of distribution network, IEEE PES General Meeting, Florida, USA, June 2007.

[4] R. Shariatinasab, J.G. Safar, H. Falaghi, Optimisation of arrester location in risk assessment in distribution network, IET Generation, Transmission \& Distribution 8(1): 151-159, 2014.

[5] R. Shariatinasab, B. Vahidi, S.H. Hosseinian, A. Ametani, Probabilistic evaluation of optimal location of surge arresters on EHV and UHV networks due to switching and lightning surges, IEEE Trans. Power Deliv. 24(4): 1903-1911, 2009.

[6] P. N. Mikropoulos, T. E. Tsovilis, A. S. Pori, Evaluation of lightning attachment and coupling models for the estimation of the lightning performance of overhead distribution lines. International Conference on Lightning Protection (ICLP), Shanghai, china, pp. 1212-1216, October 2014.

[7] R. Shariatinasab, J. G. Safar, M. A. Mobarakeh, Development of an adaptive neural-fuzzy inference system based meta-model for estimating lightning related failures in polluted environments, IET Science, Measurement \& Technology, 8 (4): 187-195, 2014.

[8] K. Sheshyekani, M. Akbari, B. Tabei, R. Kazemi, Wide-band modeling of large grounding systems to interface with electromagnetic transient solvers, IEEE Trans. Power Del. 29 (4): 1868-1876, 2014.

[9] M. R. Alemi, K. Sheshyekani, Wide-Band Modeling of Tower-Footing Grounding Systems for the Evaluation of Lightning Performance of Transmission Lines, IEEE Trans. Electromagn. Compat. 57 (6): 1627-1636, 2015.

[10]R. Shariatinasab, J. Gholinezhad, K. Sheshyekani, M.R. Alemi, The effect of wide band modeling of towerfooting grounding system on the lightning performance of transmission lines: A probabilistic evaluation, Electric Power Systems Research 141: 1-10, 2016.

[11]IEEE Lightning and Insulator Subcommittee of the T\&D Committee.: 'Parameters of lightning strokes: a review' IEEE Trans. Power Deliv. 20 (1): 346-358, 2005.

[12] IEEE Std. 1243, IEEE Guide for Improving the Lightning Performance of Transmission Lines, pp. 1-44, 1997.

[13]A. Ametani, T. Kawamura, A method of a lightning surge analysis recommended in Japan using EMTP, IEEE Trans. Power Del. 20 (2): 867-875, 2005.

[14]Z. G. Datsios, P. N. Mikropoulos, T. E. Tsovilis, Estimation of the minimum shielding failure flashover current for first and subsequent lightning strokes to overhead transmission lines, Electric Power Systems Research. 113: 141-150, 2014.

[15]J. A. Martinez, F. C. Aranda, Tower Modeling for Lightning Analysis of Overhead Transmission Lines, IEEE Trans. Power Del 2: 1212-1217, 2005.

[16]P. Sarajcev, Monte Carlo method for estimating backflashover rates on high voltage transmission lines, Electric Power Systems Research 119: 247-257, 2015.

[17]R. Shariatinasab, F. Ajri, H. Daman-Khorshid, Probabilistic evaluation of failure risk of transmission line surge arresters caused by lightning flash, IET. Generation, Transmission \& Distribution 8(2): 193202, 2014.

[18] M. Akbari, K. Sheshyekani, A. Pirayesh, F. Rachidi, M. Paolone, A. Borghetti, C.A. Nucci, Evaluation of Lightning Electromagnetic Fields and Their Induced Voltages on Overhead Lines Considering the Frequency-Dependence of Soil Electrical Parameters, IEEE Trans. Electromagn. Compat 55(6): 1210-1219, 2013.

[19]K. Sheshyekani, M. Akbari, Evaluation of LightningInduced Voltages on Multi-conductor Overhead Lines Located Above a Lossy Dispersive Ground, IEEE Trans. Power Del 29(2): 683-690, 2014.

[20] S. Visacro, R. Alipio, M. H. M. Vale, C. Pereira, The response of grounding electrodes to lightning currents: The effect of frequency-dependent soil resistivity and permittivity. IEEE Transactions on Electromagnetic Compatibility 53(2): 401-406, 2011.

[21] C. L. Longmire, K. S. Smith, A universal impedance for soils, Mission Research Corp, Santa Barbara, CA, Rep. DNA3788T, 1975.

[22]B. Gustavsen, H. M. J. De Silva, Inclusion of rational models in an electromagnetic transients program: Yparameters, Z-parameters, S-parameters, transfer functions, IEEE Trans. Power Del 28(2): 1164-1174, 2013.

[23] J.O.S. Paulino, C.F. Barbosa, I.J.S. Lopes, W.C. Boaventura, Assessment and analysis of indirect lightning performance of overhead lines, Electric Power Systems Research 118: 55-61, 2015. 
[24]J. R. Marti, Accurate modeling of frequency-dependent transmission lines in electromagnetic transient simulations, IEEE Trans. Power Appl. Syst. PAS101(1): 147-157, 1982.

[25]F. Heidler, J. M. Cvetic, B. V. Stanic, Calculation of lightning current parameters, IEEE Trans. Power Del. 14(2): 399-404, 1999.

[26] L. Grcev, M. Popov, On high-frequency circuit equivalents of a vertical ground rod, IEEE Trans. Power Del. 20(2): 15981603, 2005.

[27] K. Sheshyekani, H. R. Karami, P. Dehkhoda, M. Paolone, F. Rachidi, Application of the Matrix Pencil Method to Rational Fitting of Frequency-Domain Responses, IEEE Trans Power Del. 27(4): 2399 - 2408, 2012. 